\title{
Raman spectroscopy with 2D perturbation correlation moving windows for the characterisation of heparin-amyloid interactions
}

David J. Townsend*, David A. Middleton and Lorna Ashton.

Department of Chemistry, Lancaster University, Lancaster, LA1 4YB, United Kingdom

*Corresponding author d.townsend1@lancaster.ac.uk

\begin{abstract}
It has been shown extensively that glycosaminoglycan (GAG)-protein interactions can induce, accelerate and impede the clearance of amyloid fibrils associated with systemic and localised amyloidosis. Obtaining molecular details of these interactions is fundamental to our understanding of amyloid disease. Consequently, there is a need for analytical approaches that can identify protein conformational transitions and simultaneously characterise heparin interactions. By combining Raman spectroscopy with 2D perturbation correlation moving window (2DPCMW) analysis we have successfully identified changes in protein secondary structure during $\mathrm{pH}$ - and heparin-induced fibril formation of apolipoprotein A-I (apoA-I) associated with atherosclerosis. Furthermore, from the 2DPCMW we have identified peak shifts and intensity variations in Raman peaks arising from different heparan sulfate moieties, indicating that protein-heparin interactions vary at different heparin concentrations. Raman spectroscopy thus reveals new mechanistic insights into the role of GAGs during amyloid fibril formation.
\end{abstract}




\section{Introduction}

Amyloidosis is a collection of protein misfolding diseases, characterised by a build-up of insoluble protein fibrils with a highly conserved cross- $\beta$ structure. ${ }^{1,2}$ Amyloid deposits in tissue are associated ubiquitously with glycosaminoglycan (GAG) polysaccharides, and these clinical observations have provoked much research into the possible roles and mechanisms of GAGS in fibril formation. Heparin, a highly sulfated GAG and analogue of heparan sulfate (HS), has been extensively shown to enhance fibril formation, fibril stability and potentially decrease amyloid toxicity in several amyloidogenic proteins including $\alpha$-synuclein, amylin, A $\beta$ peptide and tau. ${ }^{3-8}$ GAGs have also been shown to promote formation of amyloid in proteins with no natural propensity to form amyloid. ${ }^{7,9,10}$ Extensive studies of heparin and HS binding have revealed that accelerated fibril formation is closely associated with electrostatic interactions and sulfate moieties, with heparin acting as a scaffold for the assembly of protein fibrils. ${ }^{3,6,11-}$ ${ }^{13}$ Fibril formation is suppressed with the removal of sulfate groups from heparin and the addition of a large excess of magnesium or calcium ions, indicating the importance of the electrostatic interactions that occur between the GAG and basic amino acid side chains of the proteins. ${ }^{7,12,13}$ However, despite continuing investigation, and the vast body of data associating heparin and other GAGs with amyloidosis, little is known about the specific mechanism involved in heparin-induced fibril formation, or indeed whether there is a common mechanism across the entire amyloid proteome. ${ }^{5-7,13}$ There is a shortage of techniques that can observe the molecular details of GAGs in heterogeneous and insoluble amyloid deposits without recourse to isotopic or fluorescent labelling of the GAG component. Here we show that Raman spectroscopy can simultaneously monitor heparin interactions with changes in protein conformation to enable detailed structural characterisation of heparin-induced amyloid formation.

The large amount of structural information available from Raman spectra of proteins makes it an ideal technique for monitoring even small alterations in protein conformations, including changes in the secondary structure ( $\alpha$-helical, $\beta$-structure and disordered elements) as well as exposure of side chain residues and binding regions. ${ }^{14-17}$ The application of $2 \mathrm{D}$ perturbation correlation moving windows (2DPCMW), a cross-correlation technique that improves the visualisation of significant spectral variations from perturbation-induced Raman data, ${ }^{18-20}$ enables these small spectral changes to be easily identified and related to perturbation transition points, e.g. specific $\mathrm{pH}$, temperature or ligand concentration that induce protein conformational changes. ${ }^{17,20,21}$ A key advantage of 2DPCMW is that rather than trying to separately compare one spectrum against another the data can be sectioned into 'windows' which enable conformation transitions associated with perturbation ranges to be identified. Furthermore, previous Raman studies have assigned specific Raman peaks to the different HS moieties, including N-sulfate $\left(\sim 1038 \mathrm{~cm}^{-1}\right), 6$ - $O$-sulfate $\left(\sim 1056 \mathrm{~cm}^{-1}\right)$ and 2 - $O$-sulfate $\left(\sim 1065 \mathrm{~cm}^{-1}\right)^{22-24}$ therefore, it should be possible to determine spectral variations that arise from both heparin and protein structures simultaneously as heparin concentration is perturbed.

We demonstrate here the sensitivity of Raman spectroscopy combined with 2DPCMW for the investigation of heparin-amyloid interactions, using as a pathologically-relevant example apolipoprotein A-I (apoA-I), the main protein component of high-density lipoprotein (HDL) 
complexes, also linked with cardiovascular disease. ${ }^{13,25-27}$ Although $~ 95 \%$ of apoA-I circulating in the body is associated in HDL particles ${ }^{28}$ the remaining $5 \%$ is able to misfold into the amyloid species with the potential to accumulate in atherosclerotic plaques, contributing to cardiovascular disease by reduced cholesterol transport, increased plaque burden and instability. ${ }^{27}$ Fibril formation and aggregation of apoA-I is accelerated under acidic conditions ${ }^{29}$ or following oxidation, ${ }^{30}$ and the insoluble apoA-I aggregates have been shown to consist of a combination of $\alpha$-helical and $\beta$-sheet components. ${ }^{25}$ Raman spectroscopy with 2DPCMW is sensitive to spectral changes arising simultaneously from both the protein and heparin's sulfate moieties during amyloid formation. A unique and powerful advantage of the technique is its ability to directly compare spectral snapshots at increasing concentration steps to identify conformational transitions in both protein and heparin as they interact providing a methodology applicable to further studies of many different GAGs and the 30 or so proteins associated with amyloid disease.

\section{Experimental}

\section{ApoA-I Expression}

Expression of human apoA-I (2-243), referred to as apoA-I for the duration of this paper, was carried out following previously published methods. ${ }^{25,31,32}$ Briefly, an N-terminally His tagged apoA-I (E2D) fusion peptide was expressed in E.Coli BL21 cells (Agilent Technologies) under the control of the T7 lac operon. Following induction with IPTG for 5 hours, the cells were harvested by centrifugation at 5,000 $\mathrm{g}$ and resuspended in cell lysis buffer [ $6 \mathrm{M} \mathrm{GnHCl}, 20$ $\mathrm{mM} \mathrm{NaH}_{2} \mathrm{PO}_{4}, 0.5 \mathrm{M} \mathrm{NaCl}$ ( $\mathrm{pH}$ 7.4)] and sonicated. Cell debris was removed by centrifugation prior to loading the lysis solution onto a $20 \mathrm{~mL}$ His Trap column (GE Healthcare). The column was washed with $20 \mathrm{mM} \mathrm{NaH} \mathrm{PO}_{4}, 0.5 \mathrm{M} \mathrm{NaCl}$ (pH 7.4) with increasing concentrations of imidazole. ApoA-I was eluted from the column with $20 \mathrm{mM} \mathrm{NaH}_{2} \mathrm{PO}_{4}, 0.5 \mathrm{M} \mathrm{NaCl}, 500 \mathrm{mM}$ imidazole ( $\mathrm{pH}$ 7.4). Fractions containing the highest protein content were pooled and dialysed against $20 \mathrm{mM}$ Tris, $1 \mathrm{mM}$ benzamidine, $1 \mathrm{mM}$ ethylenediaminetetraacetic acid ( $\mathrm{pH} 7)$. The apoA-I fusion peptide was incubated in $45 \%$ formic acid at $55{ }^{\circ} \mathrm{C}$ for 5 hours, in order to facilitate the removal of the N-terminal His tag via the acid labile Asp(2)-Pro(3) bond introduced by the E2D mutation. This resulted in an apoA-I peptide, lacking the Glu-1 Asp-2 residues. This protein was isolated from the formic acid and the $\mathrm{N}$-terminal his tag peptide via dialysis against Tris buffer, followed by dialysis into McIlvaine buffer [165 mM Na $2 \mathrm{HPO}_{4}$, $17.6 \mathrm{mM}$ citrate $(\mathrm{pH} 7)$.

\section{ApoA-I Aggregation}

Aggregation of apoA-I followed the conditions established in previous work. ${ }^{25} 200 \mu \mathrm{L}$ of apoA-I $(36 \mu \mathrm{M})$ was incubated with increasing concentration of heparin sodium salt (14-15 $\mathrm{kDa}$ Sigma Aldrich) ranging from zero to five times molar excess in McIlvaine buffer (165 $\mathrm{mM} \mathrm{Na} 2 \mathrm{HPO}_{4}, 17.6 \mathrm{mM}$ citrate $(\mathrm{pH}$ 7). Aggregation was induced with addition of a predetermined volume of concentrated hydrochloric acid (37\%) in order to reduce the sample to $\mathrm{pH}$ 4. Samples at $\mathrm{pH} 7$ were maintained in the buffer without the addition of acid, and heparin 
controls were prepared by resuspending the solid heparin directly into McIlvaine buffer at $\mathrm{pH}$ 7 , with the $\mathrm{pH}$ adjusted by addition of $\mathrm{HCl}$ accordingly. All samples (including samples at $\mathrm{pH}$ 7 and test samples of heparin without apoA-I) were then incubated at $37{ }^{\circ} \mathrm{C}$ for 3 days with agitation. Protein samples at $\mathrm{pH} 7$ and the heparin control samples were used directly after incubation. From the $\mathrm{pH} 4$ samples, fibrillar apoA-I was then pelleted by centrifugation, and the excess monomeric apoA-I, heparin and buffer was removed. The fibrils were washed 3 times with McIlvaine buffer at $\mathrm{pH} 4$. The apoA-I fibrils were resuspended in $50 \mu \mathrm{L}$ McIlvaine $\mathrm{pH} 4$.

\section{Raman spectroscopy}

Previous studies have shown that apoA-I is relatively stable in its native, predominantly $\alpha$ helical, form at $\mathrm{pH}$ 7, but under acidic conditions (e.g., $\mathrm{pH} 4$ ) it slowly assembles into insoluble fibrils with a high $\beta$-sheet content, and this process is accelerated considerably by the addition of heparin. ${ }^{30}$ In order to directly compare samples prepared at $\mathrm{pH} 7$ and $\mathrm{pH} 4$ (with and without the addition of heparin) $30 \mu \mathrm{L}$ of the solution, including any aggregated material, was deposited onto a CaFl Raman window using 3 repeat $10 \mu \mathrm{L}$ drops and left to dry at room temperature forming a thin layer / film for analysis.

All Raman spectra were collected using a confocal Raman system (InVia, Renishaw plc, Wotton-Under edge, UK), coupled to a $785 \mathrm{~nm}$ wavelength laser. Spectra were collected from the dried films using a 50x objective with a laser power at the sample of $\sim 10 \mathrm{~mW}$, exposure time of $10 \mathrm{~s}$ with 12 accumulations (total collection time $2 \mathrm{~min}$ ). 5 repeat spectra were collected and averaged from different locations within an identified region of the film e.g. either protein, buffer or heparin regions as discussed in more detail in Results and Discussion (Figure 1).

\section{Data Processing}

All data processing and 2D correlation analysis was carried out using Matlab (version R2018a) using in-house toolboxes. After cosmic spike removal all data were smoothed using a triangular average and baseline corrected using asymmetric least squares algorithm. For direct comparison of the apoA-I spectra a further pre-processing step of scaling to the maximum peak intensity of the invariant Raman peak at $1447 \mathrm{~cm}^{-1}$ (arising from $\mathrm{CH}_{2}$ groups) was required. For the heparin and buffer controls, as no protein was present, normalisation was carried out using standard normal variate (SNV) before smoothing and baseline correction.

\section{Results and Discussion}

\section{Protein film formation}

As the first step, $30 \mu \mathrm{L}$ of apoA-I solution, was deposited onto a CaFl Raman window and left to dry at room temperature forming a thin film for analysis. An extensively reported issue with film formation of protein solutions is heterogeneity across the film due to the formation of a 'coffee ring', which can be observed in Figures 1A and 1B displaying the white light images at x 5 and x 50 magnification of dried apoA-I fims. ${ }^{33-35}$ However, for the apoA-I protein samples, 
film formation provided the advantage of separating the protein from the buffer enabling Raman spectra of apoA-I with minimal buffer interference to be acquired. The spatial distribution of the protein can be exploited further to separate the signals from aggregated and unaggregated protein.

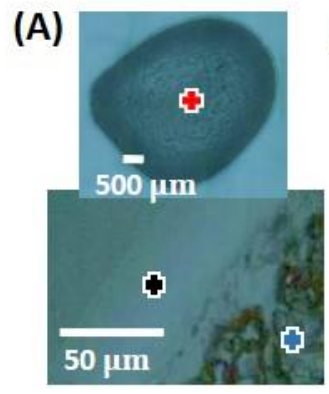

(B)
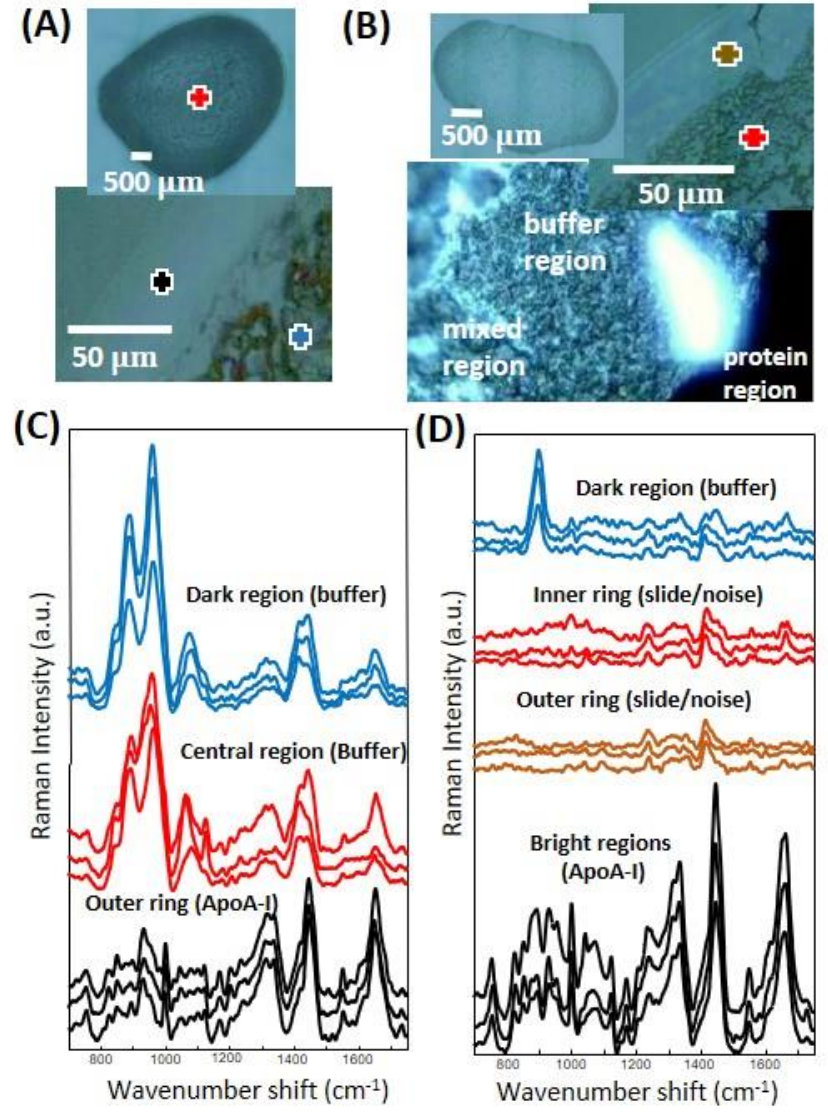

Figure 1. Thin film Raman spectra of apoA-I alone at $\mathrm{pH} 7$ and $\mathrm{pH} 4$ in the absence of heparin. (A) $\mathrm{pH} 7$ and (B) $\mathrm{pH} 4$ white light images captured using a 5x and 50x objective. (C) Spectra recorded from the $\mathrm{pH} 7$ film the inner region (red), the darker regions (blue) and the very outer ring (black) as indicated on the white light image. (D) Spectra recorded from the $\mathrm{pH} 4$ film from the bright regions (black), outer ring (brown) inner ring (red) and darker central regions (blue) as indicated on the white light image. All spectra have been smoothed and baseline corrected only.

ApoA-I is stabilised in its native, soluble form at $\mathrm{pH} 7$ in the absence of heparin. In Figure 1C spectra collected from the outer ring of the $\mathrm{pH} 7$ apoA-I -film have distinct protein peaks including strong amide I $\left(\sim 1630-1700 \mathrm{~cm}^{-1}\right)$, amide III $\left(\sim 1230-1340 \mathrm{~cm}^{-1}\right)$ and backbone $\left(\sim 870-1150 \mathrm{~cm}^{-1}\right)$ assigned peaks (Table 1$)$, whereas spectra collected from the more central and darker regions have very similar spectral features to the Raman spectra recorded from the buffer only samples (Figure SI1). Hence, monomeric, soluble protein appears to freely diffuse from the central region to the outer perimeter. ApoA-I can be induced to undergo slow aggregation at $\mathrm{pH} 4$ in the absence of heparin. The white light image of dried apoA-I at $\mathrm{pH} 4$ 
(at x5 magnification) (Figure $1 \mathrm{~B}$ ) appears to show a similar coffee ring effect. However, protein signals were not observed in the spectra collected from the outer region at $\mathrm{pH} 4$ (Figure 1C). Further observations at $\mathrm{x} 50$ magnification revealed 'bright' regions in the white light images in various locations throughout the entire $\mathrm{pH} 4$ film not observed at $\mathrm{pH}$ 7. Spectra acquired from the bright areas revealed strong protein peaks whilst spectra acquired from inner darker regions contained only buffer peaks. The lack of movement to the outer coffee ring is most likely due to the insoluble nature of the apoA-I aggregates at $\mathrm{pH} 4$. The ability to spatially segregate and spectroscopically detect monomeric and aggregated protein is a unique advantage of this method that is broadly applicable to many amyloid systems, particularly mixtures of aggregated and unaggregated material.

As a result of these important different drying effects during film formation apoA-I spectra of samples prepared at $\mathrm{pH} 7$ were acquired from the outer ring of the film and for samples prepared at $\mathrm{pH} 4$ spectra were acquired from bright regions across the sample film. Although potentially time consuming, as specific locations need to be determined across the sample, the formation of the coffee ring does allow for a direct comparison of aggregated and nonaggregated protein samples.

Table 1. Proposed Raman peak assignments for apoA-I and heparin.

\begin{tabular}{|c|c|c|}
\hline Assignment & Wavenumber $\left(\mathrm{cm}^{-1}\right)$ & Structure \\
\hline $\begin{array}{l}\text { Protein } \\
\text { amide I, C=O stretch } \\
\left(1630-1700 \mathrm{~cm}^{-1}\right) \\
\text { amide III, } \\
\mathrm{N}-\mathrm{H} \text { in plane, } \\
\mathrm{C} \alpha-\mathrm{N} \text { stretch } \\
\left(1230-1340 \mathrm{~cm}^{-1}\right) \\
\text { backbone, } \\
\text { skeletal stretch } \\
\left(870-1150 \mathrm{~cm}^{-1}\right)\end{array}$ & $\begin{array}{l}1665-1668 \\
1652 \\
1340 \\
1314 \\
1262 \\
1250 \\
1240 \\
1060-1090 \\
950 \\
932\end{array}$ & $\begin{array}{l}\beta \text {-sheet, narrows with aggregation } \\
\text { Buried } \alpha \text {-helix } \\
\\
\alpha 6,37 \\
\alpha \text {-helix }{ }^{38,39} \\
\alpha \text {-helix } \\
\alpha \text {-helix } \\
\alpha 9,40 \\
\text { Disordered structure }^{39,41} \\
\beta \text {-sheet } \\
\\
\text { Intermolecular sheet interactions }^{42,43} \\
\text { Disordered structure }^{42,43} \\
\alpha \text {-helix }\end{array}$ \\
\hline Side Chain Residues & $\begin{array}{l}1554 \\
1208 \\
1003 \\
850 \\
828 \\
755\end{array}$ & $\begin{array}{l}\text { Trp } \\
\text { Tyr }^{44,45} \\
\text { Phe }^{17,45} \\
\text { Tyr Fermi Double } \\
\text { Tyr Fermi Double } \\
\text { Trp indole ring } \\
\text { T0,45 }\end{array}$ \\
\hline Heparin & $\begin{array}{l}1038 \\
1056 \\
1065\end{array}$ & $\begin{array}{l}\text { N-sulfate, symmetric S-O stretch } \\
\text { 6-O-sulfate, } \\
\text { stretch }^{22,23}\end{array}$ \\
\hline
\end{tabular}



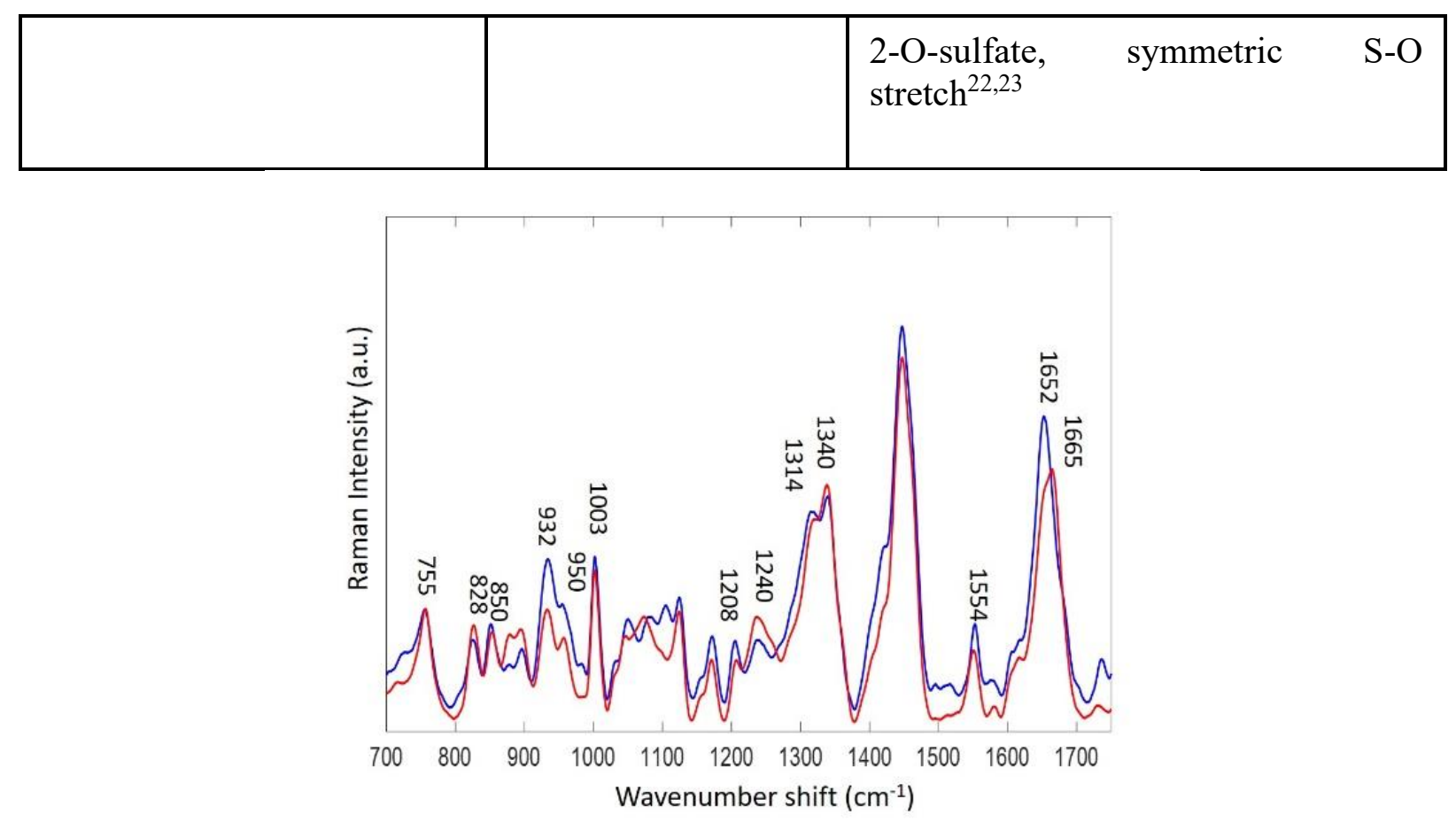

Figure 2. Averaged Raman spectra $(n=5)$ of apoA-I acquired from thin films prepared at $\mathrm{pH} 7$ (blue) and pH 4 (red).

Figure 2 displays the averaged Raman spectra of apoA-I prepared at $\mathrm{pH} 7$ and $\mathrm{pH} 4$. A large number of consistent protein features can be observed in both spectra, including Raman peaks arising from $\beta$-structure, $\alpha$-helix and side chain orientation of tyrosine, tryptophan and phenylalanine (Table 1). The Raman spectrum of apoA-I at pH 7 indicates the predominance of $\alpha$-helical structure with intense peaks observed at 932 and $1652 \mathrm{~cm}^{-1}$ which agrees with previous studies reporting apoA-I at pH 7 as having over $50 \% \alpha$-helical structure. ${ }^{25}$ When compared with the Raman spectra acquired at $\mathrm{pH} 4$ a decrease in peak intensity can be observed at $\sim 932 \mathrm{~cm}^{-1}$ indicating a reduction but not complete loss of $\alpha$-helical secondary structure with changing $\mathrm{pH}$. In the amide I region, arising from $\mathrm{C}=\mathrm{O}$ stretch of the peptide backbone, there is a loss of intensity at $1652 \mathrm{~cm}^{-1}$ with a shift to $1665 \mathrm{~cm}^{-1}$. This wavenumber shift, along with the increase in intensity observed at $1240 \mathrm{~cm}^{-1}$ arising from $\mathrm{C}-\mathrm{N}$ stretch and $\mathrm{N}-\mathrm{H}$ bend, indicates an increase in $\beta$-sheet and potentially disordered structure at $\mathrm{pH} 4$ compared to $\mathrm{pH} 7$ (Table 1). Similar structural changes were also reported after investigations into apoA-I aggregation by SRCD where fitting of spectra suggested a partial loss of helical content and a gain of $\beta$-sheet and disordered elements. ${ }^{25}$ In Figure 2 the peak at $950 \mathrm{~cm}^{-1}$ assigned to disordered structure is more distinct in the spectrum acquired at $\mathrm{pH} 4$ compared to $\mathrm{pH} 7$ and may also indicate an increase is disordered elements.

\section{Heparin-induced spectral variation}

As previously discussed, heparin binding to several amyloidogenic proteins have been shown to rapidly induce amyloid formation.; CD and NMR spectroscopy can determine heparininduced structural changes and map binding sites on the fibrils, ${ }^{47}$ but cannot easily visualise 
bound or other GAGs, and this is where Raman spectroscopy can provide new insights into the role of heparin in the aggregation process. In the case of ApoA-I, the protein undergoes instantaneous aggregation into amyloid-like fibrils in the presence of heparin at $\mathrm{pH} 4$. Figure 3A displays the Raman spectra of apoA-I at $\mathrm{pH} 4$ and $\mathrm{pH} 7$, with and without heparin, at a 1:5 molar excess concentration. When the spectra of ApoA-I at pH 4 with and without heparin are compared heparin assigned peaks in the region $\sim 1020-1100 \mathrm{~cm}^{-1}$ (Figure SI2) can be clearly observed alongside variations in peaks assigned to protein structural features, demonstrating the ability of Raman spectroscopy to determine heparin interactions and conformational changes simultaneously. A decrease in peak intensity can be observed at 1314 and $1340 \mathrm{~cm}^{-1}$ as well as a large increase in the peak intensity at $1240 \mathrm{~cm}^{-1}$ indicating a greater loss of $\alpha$ helical structure and an increase in $\beta$-sheet at $\mathrm{pH} 4$ with the addition of heparin.

Interestingly, heparin peaks are not observed at $\mathrm{pH} 7$ even at a 1:5 molar excess over apoA-I (Figure 3A) and protein assigned peaks show no variation with the addition of heparin suggesting a lack of protein-heparin interaction. The white light images of the $\mathrm{pH} 7$ films exhibit two outer rings and a dark inner region. Spectra from these three regions indicate that heparin separates from the protein and buffer during film formation at $\mathrm{pH}$ 7. In Figure 3B heparin spectral features in the region $1020-1100 \mathrm{~cm}^{-1}$ can be observed in the spectra collected from the inner ring of the dried film but no protein features are observed. In contrast, spectra collected from the very outer region display only protein features with no heparin assigned peaks observed suggesting complete separation of protein from heparin during film formation. The spectrum from this region contains no signature peaks signifying $\beta$-sheet formation, implying that the protein retains its predominantly $\alpha$-helical fold. Consequently, heparin binds weakly or not at all to apoA-I in its native form at $\mathrm{pH} 7$, whereas at $\mathrm{pH} \mathrm{4}$, the combination of heparin with reduced $\alpha$-helical structure, increased disordered and $\beta$-structures results in further aggregation. At $\mathrm{pH} 4$ the heparin peaks colocalize with the protein peaks at all positions, indicating that heparin is incorporated into the fibrils. Heparin binding must therefore occur only after partial structural rearrangement in the protein induced by low $\mathrm{pH}$, or as a result of protonation of key heparin-binding residues (e.g., histidines). 


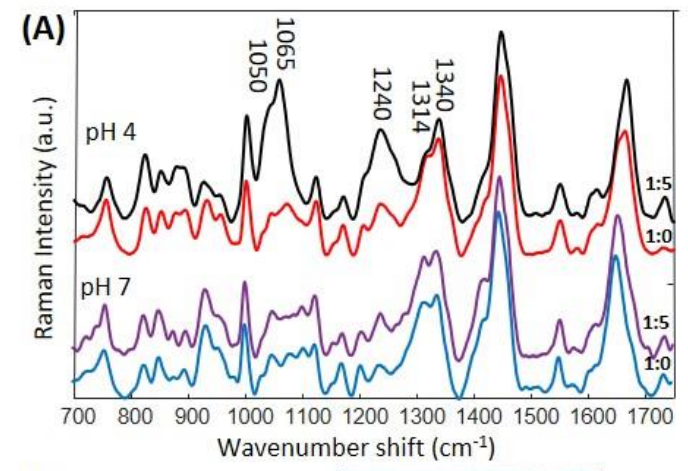

(B)
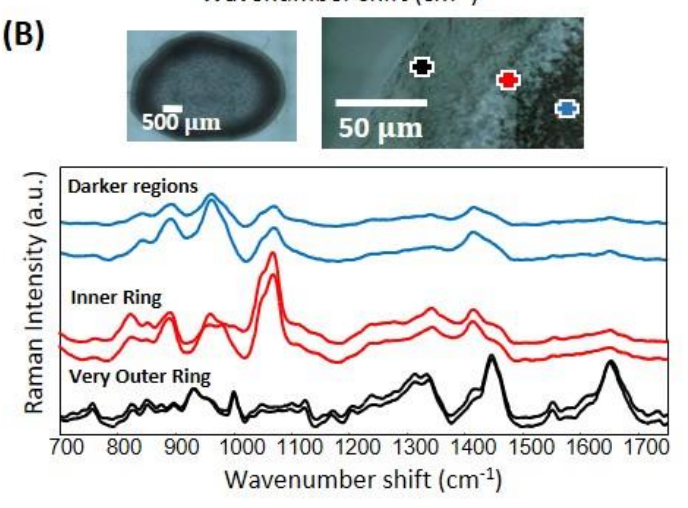

Figure 3. Thin film Raman spectra of apoA-I in the presence of heparin. (A) Average Raman spectra $(n=5)$ of apoA-I with (1:5) and without (1:0) heparin at a 1:5 molar ratio prepared at $\mathrm{pH} 7$ and $\mathrm{pH}$ 4.(B) White light images of apoA-I:heparin films at $\mathrm{pH} 7$ with 5 molar excess of heparin and averaged Raman spectra $(n=5)$ acquired from the very outer ring (black), inner ring (red) and darker regions (blue).

\section{$2 D$ Correlation analysis}

Further information about heparin-protein interactions during aggregation can be gained using 2D correlation spectroscopy (2DCOS). 2D correlation spectroscopy (2DCOS) is a crosscorrelation technique that simplifies a spectral data set obtained over some systematically varied perturbation, such as incremented temperature, concentration or $\mathrm{pH}$, by displaying relative similarities and differences as contour plots. ${ }^{19,20}$ In particular, 2D perturbation correlation moving windows (2DPCMW) contour plots have the advantage of directly relating spectral variations to the perturbation by separating the data into smaller windows to locate key transitional points. ${ }^{17,18,20}$ 2DPCMW contour plots are usually displayed as a function of spectral wavenumber against average translating perturbation resulting in groups of contours that are either positive or negative in value, with distinct shapes that indicate the extent and direction of spectral variations occurring at the corresponding peak wavenumber.

Here, we demonstrate that 2DPCMW provides insights into the molecular details accompanying amyloid formation in the presence of increasing concentrations of heparin, from the perspective of the protein and the GAG simultaneously. Figure 4 displays the 2DPCMW of heparin-concentration induced spectral variations for apoA-I at $\mathrm{pH} 4$ where positive contours (shaded red) indicate increasing peak intensity and negative contours (shaded blue) indicate 
decreasing peak intensity at apoA-I:heparin ratio ranges with the relative extent of intensity change indicated by the number of contours.
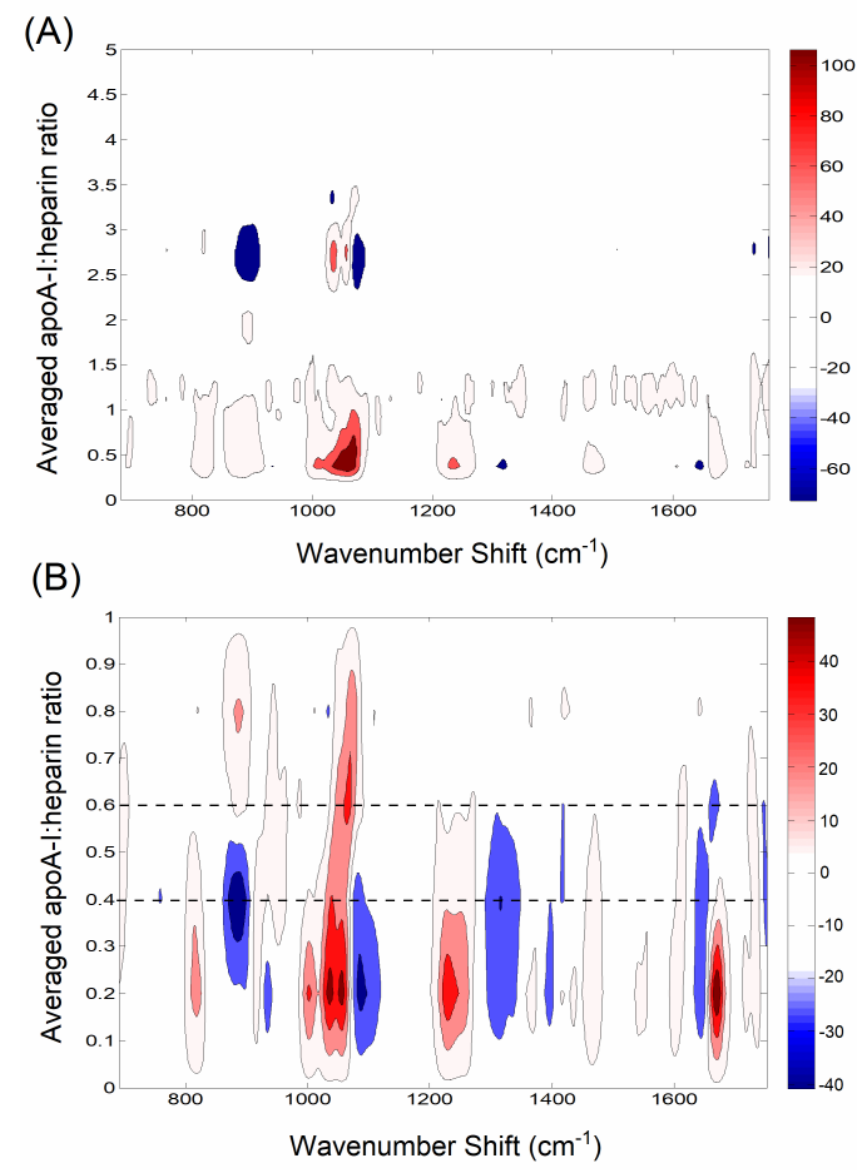

Figure 4. 2DPCMW plots of heparin-induced aggregation in apoA-I at $\mathrm{pH}$ 4. Heparin concentration was varied (A) from 0 to 5 excess molar concentration of heparin and (B) 0 to molar equivalence with apoA-I. 2DPCMW plotted as a function of spectral wavenumber and average translating window ratio. Contours shaded red indicate peaks that are increasing in intensity with increasing heparin concentration while blue shading indicates decreasing peak intensity with increasing concentration.

In Figure 4A where the apoA-I:heparin molar ratio was increased in 0.5 concentration steps up to a 5-fold molar excess over apoA-I, the majority of contours, and therefore spectral variations, are observed between apoA-I:heparin molar ratios of 1:0 and 1:1 with very few contours observed above 1:1 ratio. Small contours can be observed at 898 and $1020-1100 \mathrm{~cm}^{-1}$ at 1:2.51:3 excess molar ratio, which may be due to the slight influence of buffer or heparin peaks observed in the protein spectra as a result of reduced separation during thin film formation at the higher apoA-I:heparin ratios (Figures SI3 and SI4). The lack of further contours in the heparin assigned region $1020-1100 \mathrm{~cm}^{-1}$ suggest that no additional heparin colocalises with the insoluble apoA-I at these higher ratios and that free heparin may either interact with the buffer or dry separately during film formation. Hence, the 2DPCMW method indicates that no further binding occurs above the apoA-I:heparin molar ratio of $1: 1$. 
As the majority of spectral variations are observed below a ratio of 1:1 additional spectra were collected in 0.2 steps (example spectra shown in Figure SI5) and the 2DPCMW is shown in Figure 4B, where three potential possible structural transitions can be identified as the heparin concentration is increased.

With the exception of the buffer and heparin assigned peaks at 898 and $1020-1100 \mathrm{~cm}^{-1}$, all major variations in the spectra cease above the molar ratio of 1:0.6 suggesting that the majority of protein structural changes take place below this concentration. It should be noted that the amyloid:heparin samples were obtained after 3 days of incubation and the spectra detect the species present at end-point of the aggregation process. Negative contours are assigned to the loss of $\alpha$-helix and positive contours assigned to $\beta$-sheet formation and aromatic side chain reorientation (Table 2). These structural changes are not observed by CD spectroscopy because the rapid precipitation of the protein during aggregation gives rise to a considerable loss of signal (Figure SI7). When examined closely the two sets of positive contours arising from $\beta$ sheet assigned peaks stop at different apoA-I:heparin ratios with the peak at $1668 \mathrm{~cm}^{-1}$ no longer changing in intensity after $\sim 1: 0.4$ whilst the peak at $1240 \mathrm{~cm}^{-1}$ continues to increase in intensity until a ratio of 1:0.6, suggesting two possible transition stages one from $0-0.4$ and a second from 0.4-0.6. Identifying these separate but subtle differences in conformational transitions is difficult from visual inspection of the spectra alone (Figurs SI5) demonstrating the potential of 2DPCMW to aid spectral analysis of data sets. A previous Raman study of $\mathrm{pH}-$ induced amyloid formation in $\alpha$-synuclein in the absence of heparin reported similar discrepancies in behaviour of the two $\beta$-sheet assigned peaks associated with the formation of longer fibrils. ${ }^{8}$ As previously stated, peaks in the amide I region $\left(1630-1700 \mathrm{~cm}^{-1}\right)$ arise from $\mathrm{C}=\mathrm{O}$ stretching whilst peaks in the amide III region $\left(1230-1340 \mathrm{~cm}^{-1}\right)$ arise from C-N stretching and N-H bending. The continued increase in intensity at $1240 \mathrm{~cm}^{-1}$ compared to the $1668 \mathrm{~cm}^{-1}$ may indicate a change, or elongation, in fibril formation with increasing heparin concentration.

Table 2. Summary of the spectral variations for apoA-I detected by 2DPCMW.

\begin{tabular}{cccll}
\hline $\begin{array}{c}\text { Wavenumber shift } \\
\left(\mathrm{cm}^{-1}\right)\end{array}$ & Intensity & $\begin{array}{c}\text { apoA-I:heparin } \\
\text { molar ratio }\end{array}$ & Assignment & \\
\hline 828 & $\uparrow$ & $0.0-0.5$ & \multicolumn{2}{l}{ Tyrosine side chain reorientation } \\
1003 & $\uparrow$ & $0.0-0.4$ & $\begin{array}{l}\text { Phenylalanine } \\
\text { reorientation }\end{array}$ & side chain \\
1240 & $\uparrow$ & $0.0-0.6$ & $\beta$-sheet formation & \\
1314 & $\downarrow$ & $0.1-0.6$ & Loss of $\alpha$-helix & \\
1652 & $\downarrow$ & $0.1-0.6$ & Loss of $\alpha$-helix & \\
1668 & $\uparrow$ & $0.0-0.4$ & -sheet formation & \\
\hline
\end{tabular}

As well as reporting heparin-induced protein conformational changes, correlation analysis reveals new insights from the perspective of heparin. Interestingly, in the 2DPCMW plot (Figure 4B) in the first transition stage from 1:0 to 1:0.4 molar ratio, distinct contours from heparin assigned peaks can be observed at 1038 and $1056 \mathrm{~cm}^{-1}$; however, above 1:0.4 ratio 
these peaks merge and shift to $1065 \mathrm{~cm}^{-1}$ which continues to the ratio of $1: 1$. In the spectrum of heparin alone (Figure SI2), potential overlapping peaks can be observed at 1038, 1056 and $1065 \mathrm{~cm}^{-1}$ (Figure SI4), which have beenassigned to the $\mathrm{N}$-sulfate, 6-O-sulfate, and 2-O-sulfate of the symmetric S-O stretch, respectively. ${ }^{22-24}$ One well documented advantage of 2DCOS is the ability to identify differences in behaviour in overlapping bands which are difficult to determine in the spectra. Raman spectra from thin films of heparin only, at concentrations comparable to those used in the apoA-I:heparin measurements show a typical increase in peak intensity with increasing concentration (Figure SI6), butno shift in peak position or intensity variation between the overlapping peaks can be observed in absence of apoA-I. The changes seen in the presence of protein most likely arise from differences in heparin binding to apoA-I above and below the molar ratio of 1:0.4.

A mechanism can be proposed that accounts for the heparin-dependent changes in the Raman spectra. Native folded apoA-I is a stable helical bundle and does not have exposed binding sites for heparin, but acidic conditions may stabilise the so-called "beta-clasp" structure of lipid-free apoA-I in which four anti-parallel $\beta$-strands are proposed to form at the $\mathrm{N}$ - and C-termini. ${ }^{48,49}$ Lower concentrations of heparin may bind to these regions and nucleate self-assembly of the strands, rapidly exhausting the concentration of free heparin. At higher concentrations the excess heparin may bind to different sites on the elongating fibrils, hence accounting for the different spectral changes observed at higher heparin:apoA-I molar ratios.

\section{Conclusion}

We have demonstrated the unique sensitivity of Raman spectroscopy combined with 2D correlation analysis, in particular 2DPCMW, to investigate the interactions between the GAGproxy heparin and amyloid fibrils. The methodology offers new insights the structure and composition of amyloid fibrils and is complementary to more established structural methods. The spectra report on both the protein and saccharide components of the insoluble fibrils without modification or labelling. In the specific example studied, a partial loss of helical content in apoA-I is observed alongside an increase $\beta$-sheet and disordered elements and the importance of each specific sulfate moiety in directing fibril formation can be identified. Perturbations of bands 1100 and $1400 \mathrm{~cm}-1$ have been attributed to conformational changes in the rings. ${ }^{50}$ Here, the observed changes may be due to a shift in the dynamic equilibrium between the ${ }^{1} \mathrm{C}_{4}$ chair and ${ }^{2} \mathrm{~S}_{0}$ skew boat forms $\left(67: 33{ }^{1} \mathrm{C}_{4}:{ }^{2} \mathrm{~S}_{0}\right)$. This could be tested further using model compounds of known conformation.

A unique advantage of the method is the ability to spatially separate monomeric protein from aggregated protein and from free heparin, revealing new insights into the heparin binding mechanism. It is envisaged that this method can equally be applied to other GAG-dependent amyloidogenic proteins, such as tau, amyloid- $\beta$ and functional amyloid systems, to report commonalities or protein-sequence specific differences in GAG induced amyloidosis. 


\section{Acknowledgements}

This work was funded in part by the British Heart Foundation (grant FS/13/28/30208).

\section{Author Contributions}

L.A and D.T devised the project. Experiments were designed and conducted by L.A and D.T, and data was analysed and reviewed by L.A, D.T and D.M. L.A drafted the manuscript, and all authors contributed its revision. The authors declare no conflicts of interest.

\section{Supporting Information}

SI1. Raman spectra of buffers

SI2. Raman spectra of heparin

SI3. Raman spectra of apoA-I at $\mathrm{pH} 4$ with increasing molar excess of heparin from 0-5

SI4. Repeat Raman spectra of apoA-I with 5 molar excess of heparin

SI5. Raman spectra of apoA-I at pH 4 with heparin molar ratios of 0-1

SI6. Raman spectra and intensity of increasing heparin concentrations with PCMW

SI7. ApoA-I aggregation monitored by ThT fluorescence, CD, and TEM.

SI8. Chemical structure of sulphated heparin disaccharide

\section{References}

1. Sipe, J. D.; Benson, M. D.; Buxbaum, J. N.; Ikeda, S.; Merlini, G.; Saraiva, M. J. M.; Westermark, P., Nomenclature 2014: Amyloid fibril proteins and clinical classification of the amyloidosis. Amyloid-Journal of Protein Folding Disorders 2014, 21 (4), 221-224.

2. Chiti, F.; Dobson, C. M., Protein misfolding, functional amyloid, and human disease. Annual Review of Biochemistry 2006, 75, 333-366.

3. McLaurin, J.; Franklin, T.; Zhang, X. Q.; Deng, J. P.; Fraser, P. E., Interactions of Alzheimer amyloid-beta peptides with glycosaminoglycans - Effects on fibril nucleation and growth. European Journal of Biochemistry 1999, 266 (3), 1101-1110.

4. Cohlberg, J. A.; Li, J.; Uversky, V. N.; Fink, A. L., Heparin and other glycosaminoglycans stimulate the formation of amyloid fibrils from alpha-synuclein in vitro. Biochemistry 2002, 41 (5), 1502-1511.

5. $\quad$ Stewart, K. L.; Hughes, E.; Yates, E. A.; Middleton, D. A.; Radford, S. E., Molecular Origins of the Compatibility between Glycosaminoglycans and A beta 40 Amyloid Fibrils. Journal of molecular biology 2017, 429 (16), 2449-2462.

6. Mehra, S.; Ghoshn, D.; Kumar, R.; Mondal, M.; Gadhe, L. G.; Das, S.; Anoop, A.; Jha, N. N.; Jacob, R. S.; Chatterjee, D.; Ray, S.; Singh, N.; Kumar, A.; Maji, S. K., 
Glycosaminoglycans have variable effects on alpha-synuclein aggregation and differentially affect the activities of the resulting amyloid fibrils. Journal of Biological Chemistry 2018, 293 (34), 12975-12991.

7. Iannuzzi, C.; Irace, G.; Sirangelo, I., The Effect of Glycosaminoglycans (GAGs) on Amyloid Aggregation and Toxicity. Molecules 2015, 20 (2), 2510-2528.

8. Flynn, J. D.; McGlinchey, R. P.; Walker, R. L.; Lee, J. C., Structural features of alphasynuclein amyloid fibrils revealed by Raman spectroscopy. Journal of Biological Chemistry 2018, 293 (3), 767-776.

9. $\quad$ Nitani, A.; Muta, H.; Adachi, M.; So, M.; Sasahara, K.; Sakurai, K.; Chatani, E.; Naoe, K.; Ogi, H.; Hall, D.; Goto, Y., Heparin-dependent aggregation of hen egg white lysozyme reveals two distinct mechanisms of amyloid fibrillation. Journal of Biological Chemistry 2017, 292 (52), 21219-21230.

10. Madine, J.; Davies, H. A.; Hughes, E.; Middleton, D. A., Heparin Promotes the Rapid Fibrillization of a Peptide with Low Intrinsic Amyloidogenicity. Biochemistry 2013, 52 (50), 8984-8992.

11. Castillo, G. M.; Lukito, W.; Wight, T. N.; Snow, A. D., The sulfate moieties of glycosaminoglycans are critical for the enhancement of beta-amyloid protein fibril formation. Journal of Neurochemistry 1999, 72 (4), 1681-1687.

12. Motamedi-Shad, N.; Monsellier, E.; Chiti, F., Amyloid Formation by the Model Protein Muscle Acylphosphatase is Accelerated by Heparin and Heparan Sulphate Through a Scaffolding-based Mechanism. Journal of Biochemistry 2009, 146 (6), 805-814.

13. Mikawa, S.; Mizuguchi, C.; Nishitsuji, K.; Baba, T.; Shigenaga, A.; Shimanouchi, T.; Sakashita, N.; Otaka, A.; Akaji, K.; Saito, H., Heparin promotes fibril formation by the $\mathrm{N}$-terminal fragment of amyloidogenic apolipoprotein A-I. Febs Letters 2016, 590 (20), 34923500 .

14. Tuma, R., Raman spectroscopy of proteins: from peptides to large assemblies. Journal of Raman Spectroscopy 2005, 36 (4), 307-319.

15. Pelton, J. T.; McLean, L. R., Spectroscopic methods for analysis of protein secondary structure. Analytical Biochemistry 2000, 277 (2), 167-176.

16. Ettah, I.; Ashton, L., Engaging with Raman Spectroscopy to Investigate Antibody Aggregation. Antibodies 2018, 7 (3), 1-12.

17. Ettah, I.; Ashton, L., Determination, of Phosphorylation and Deprotonation Induced Higher Order Structural Transitions in alpha(s)-Caseins. Analytical Chemistry 2019, 91 (21), 13940-13946.

18. Morita, S., Perturbation-correlation moving-window two-dimensional correlation spectroscopy. Applied Spectroscopy. 2006, 60 (4), 398-406.

19. Noda, I.; Ozaki, Y., Two-dimensional correlation spectroscopy: applications in vibrational and optical spectroscopy. John Wiley \& Sons: 2005.

20. Gömez De La Cuesta, R.; Goodacre, R.; Ashton, L., Monitoring antibody aggregation in early drug development using raman spectroscopy and perturbation-correlation moving windows. Analytical Chemistry 2014, 86 (22), 11133-11140.

21. Brewster, V. L.; Ashton, L.; Goodacre, R., Monitoring the glycosylation status of proteins using raman spectroscopy. Analytical Chemistry 2011, 83 (15), 6074-6081.

22. Atha, D. H.; Gaigalas, A. K.; Reipa, V., Structural analysis of heparin by Raman spectroscopy. Journal of Pharmaceutical Sciences 1996, 85 (1), 52-56.

23. Miller, G. J.; Hansen, S. U.; Barath, M.; Johannessen, C.; Blanch, E. W.; Jayson, G. C.; Gardiner, J. M., Synthesis of a heparin-related GlcN-IdoA sulfation-site variable disaccharide library and analysis by Raman and ROA spectroscopy. Carbohydrate Research 2014, 400, 44-53. 
24. Cabassi, F.; Casu, B.; Perlin, A. S., Infared-absorption and raman-scattering of sulfate groups of heparin and related glycosaminoglycans in aqueous-solution. Carbohydrate Research 1978, 63 (JUN), 1-11.

25. Townsend, D.; Hughes, E.; Hussain, R.; Siligardi, G.; Baldock, S.; Madine, J.; Middleton, D. A., Heparin and Methionine Oxidation Promote the Formation of Apolipoprotein A-I Amyloid Comprising alpha-Helical and beta-Sheet Structures. Biochemistry 2017, 56 (11), 1632-1644.

26. Oram, J. F.; Vaughan, A. M., ATP-binding cassette cholesterol transporters and cardiovascular disease. Circulation Research 2006, 99 (10), 1031-1043.

27. Mucchiano, G. I.; Haggqvist, B.; Sletten, K.; Westermark, P., Apolipoprotein A-Iderived amyloid in atherosclerotic plaques of the human aorta. Journal of Pathology 2001, 193 (2), 270-275.

28. Rye, K. A.; Barter, P. J., Formation and metabolism of prebeta-migrating, lipid-poor apolipoprotein A-I. Arteriosclerosis Thrombosis and Vascular Biology 2004, 24 (3), 421-428. 29. Ramella, N. A.; Schinella, G. R.; Ferreira, S. T.; Prieto, E. D.; Vela, M. E.; Rios, J. L.; Tricerri, M. A.; Rimoldi, O. J., Human Apolipoprotein A-I Natural Variants: Molecular Mechanisms Underlying Amyloidogenic Propensity. Plos One 2012, 7 (8), e43755.

30. Wong, Y. Q.; Binger, K. J.; Howlett, G. J.; Griffin, M. D. W., Identification of an amyloid fibril forming peptide comprising residues 46-59 of apolipoprotein A-I. Febs Letters 2012, 586 (13), 1754-1758.

31. Oda, M. N.; Bielicki, J. K.; Berger, T.; Forte, T. M., Cysteine substitutions in apolipoprotein A-I primary structure modulate paraoxonase activity. Biochemistry 2001, 40 (6), 1710-1718.

32. Ryan, R. O.; Forte, T. M.; Oda, M. N., Optimized bacterial expression of human apolipoprotein A-I. Protein Expr. Purif. 2003, 27 (1), 98-103.

33. Filik, J.; Stone, N., Drop coating deposition Raman spectroscopy of protein mixtures. Analyst 2007, 132 (6), 544-550.

34. Carreon, Y. J. P.; Rios-Ramirez, M.; Moctezuma, R. E.; Gonzalez-Gutierrez, J., Texture analysis of protein deposits produced by droplet evaporation. Scientific reports 2018, 8.

35. Carreon, Y. J. P.; Gonzalez-Gutierrez, J.; Perez-Camacho, M. I.; Mercado-Uribe, H., Patterns produced by dried droplets of protein binary mixtures suspended in water. Colloids and Surfaces B-Biointerfaces 2018, 161, 103-110.

36. Takekiyo, T.; Imai, T.; Kato, M.; Taniguchi, Y., Understanding high pressure stability of helical conformation of oligopeptides and helix bundle protein - High Pressure FT-IR and RISM Theoretical Studies. Biochimica Et Biophysica Acta-Proteins and Proteomics 2006, 1764 (3), 355-363.

37. Maiti, N. C.; Apetri, M. M.; Zagorski, M. G.; Carey, P. R.; Anderson, V. E., Raman spectroscopic characterization of secondary structure in natively unfolded proteins: $\alpha-$ synuclein. Journal of the American Chemical Society 2004, 126 (8), 2399-2408.

38. Tsuboi, M.; Suzuki, M.; Overman, S. A.; Thomas, G. J., Intensity of the Polarized Raman Band at 1340-1345 cm-1 As an Indicator of Protein $\alpha$-Helix Orientation: Application to Pf1 Filamentous Virus. Biochemistry 2000, 39 (10), 2677-2684.

39. Ashton, L.; Barron, L. D.; Hecht, L.; Hyde, J.; Blanch, E. W., Two-dimensional Raman and Raman optical activity correlation analysis of the $\alpha$-helix-to-disordered transition in poly(L-glutamic acid). Analyst 2007, 132 (5), 468-479.

40. Liang, M.; Chen, V. Y.; Chen, H.-L.; Chen, W., A simple and direct isolation of whey components from raw milk by gel filtration chromatography and structural characterization by Fourier transform Raman spectroscopy. Talanta 2006, 69 (5), 1269-1277. 
41. Ellepola, S.; Choi, S.-M.; Phillips, D.; Ma, C.-Y., Raman spectroscopic study of rice globulin. Journal of Cereal Science 2006, 43 (1), 85-93.

42. Ashton, L.; Barron, L. D.; Czarnik-Matusewicz, B.; Hecht, L.; Hyde, J.; Blanch, E. W., Two-dimensional correlation analysis of Raman optical activity data on the alpha-helixto-beta-sheet transition in poly(L-lysine). Molecular Physics 2006, 104 (9), 1429-1445.

43. Howell, N.; Li-Chan, E., Elucidation of interactions of lysozyme with whey proteins by Raman spectroscopy. International journal of food science \& technology 1996, 31 (5), 439451.

44. Prevelige, P. E.; Thomas, D.; Aubrey, K. L.; Towse, S. A.; Thomas, G. J., Studies of virus structure by raman-spectroscopy .37. Subunit conformational-changes accompanying bacteriophage-p22 capsid maturation. Biochemistry 1993, 32 (2), 537-543.

45. Hernández, B.; Coïc, Y. M.; Pflüger, F.; Kruglik, S. G.; Ghomi, M., All characteristic Raman markers of tyrosine and tyrosinate originate from phenol ring fundamental vibrations. Journal of Raman Spectroscopy 2016, 47 (2), 210-220.

46. Siamwiza, M. N.; Lord, R. C.; Chen, M. C.; Takamatsu, T.; Harada, I.; Matsuura, H.; Shimanouchi, T., Interpretation of the doublet at 850 and $830 \mathrm{~cm}-1$ in the Raman spectra of tyrosyl residues in proteins and certain model compounds. Biochemistry 1975, 14 (22), 4870-4876.

47. Stewart, K. L.; Hughes, E.; Yates, E. A.; Akien, G. R.; Huang, T. Y.; Lima, M. A.; Rudd, T. R.; Guerrini, M.; Hung, S. C.; Radford, S. E.; Middleton, D. A., Atomic Details of the Interactions of Glycosaminoglycans with Amyloid-beta Fibrils. Journal of the American Chemical Society 2016, 138 (27), 8328-8331.

48. Lagerstedt, J. O.; Budamagunta, M. S.; Liu, G. S.; DeValle, N. C.; Voss, J. C.; Oda, M. N., The "beta-clasp" model of apolipoprotein A-I--a lipid-free solution structure determined by electron paramagnetic resonance spectroscopy. Biochim Biophys Acta 2012, 1821 (3), 44855 .

49. Oda, M. N., Lipid-free apoA-I structure - Origins of model diversity. Biochim. Biophys. Acta Mol. Cell Biol. Lipids 2017, 1862 (2), 221-233.

50. TR Rudd, R Hussain, G Siligardi, EA Yates, Raman and raman optical activity of glycosaminoglycans, Chem Comm 2010, 23, 4124-4126.

\section{For Table of Contents Only}

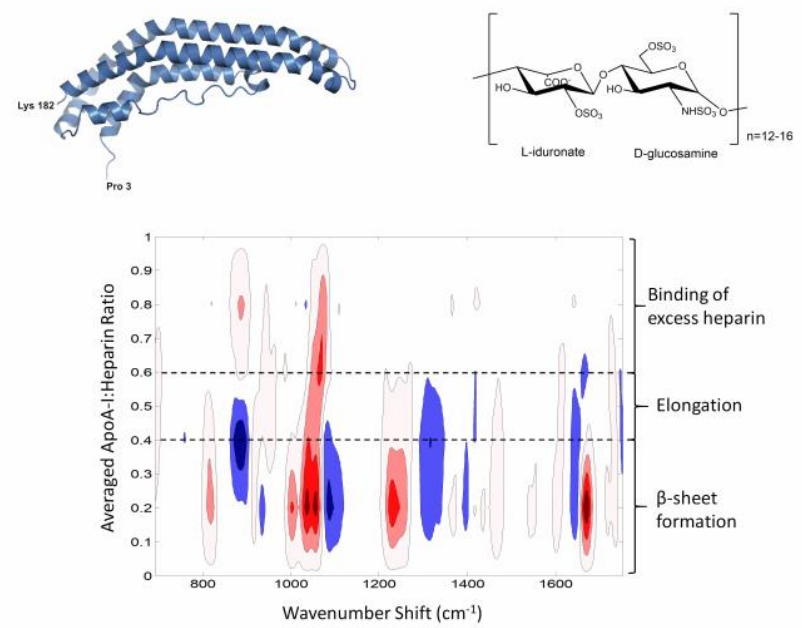

